\title{
Guerreiro Ramos e o Instituto Superior de Estudos Brasileiros (ISEB)
}

\author{
Moema Toscano \\ Universidade Federal do Rio de Janeiro (aposentada) \\ E-mail: moema.toscanoilha@gmail.com
}

\begin{abstract}
Conheci Alberto Guerreiro Ramos por volta de 1956, quando era criado o Instituto Superior de Estudos Brasileiros (ISEB), uma instituição que para nós, universitários da Faculdade Nacional de Filosofia, era novidade. O ISEB era uma instituição de ensino que não se enquadrava na academia formal. Na nossa experiência, a fonte de autoridade para um docente ensinar era o fato de ele pertencer a uma faculdade, de ter feito um curso de faculdade, enfim, de ter vínculos com uma instituição de ensino superior regular, reconhecido; isso é que era o normal. E Guerreiro Ramos aparecia nessa instituição, o ISEB, criada fora dos trâmites normais das instituições acadêmicas, mas que se ocupava da reflexão sobre o Brasil da época. Nós estávamos muito interessados em tentar entender o processo do desenvolvimento brasileiro, mas estávamos meio às cegas. Para nós, ainda não havia parâmetros para essa reflexão.
\end{abstract}

Nós estudávamos filosofia, sociologia geral, mas não era nada que se aplicasse especificamente ao Brasil. A novidade que o ISEB trazia era essa. Aí residia o grande interesse que nós, os grupos de estudiosos das diferentes faculdades, manifestamos desde o início: ver o que se discutia em uma instituição não acadêmica em que os professores não exibiam a credencial acadêmica, a formação tradicional. Sabíamos que eram pessoas que tinham conhecimento; eram autoridades em suas áreas, mas essa autoridade nem sempre se formalizava na burocracia acadêmica. Então a coisa começou por aí, por esse interes- 
se: vamos ver o que se faz aqui no ISEB, o que se estuda aqui, quem são essas pessoas e o que elas têm a dizer para nós sobre o tema do desenvolvimento do Brasil.

Guerreiro Ramos estava dentro desse contexto. Ele ainda não tinha reconhecimento como autoridade no campo das faculdades de filosofia; não era conhecido como alguém que vinha de uma faculdade. Por outro lado, nem sempre a ligação com a faculdade implicava no engajamento da pessoa na atividade docente. Muitos professores, referências nas faculdades, desenvolviam suas carreiras sem se ocupar muito com o ensino. Aliás, era quase uma tradição que os melhores professores não dessem aula. Havia aquela figura do catedrático: muitas vezes os catedráticos não davam aulas. Quem dava aula eram assistentes e ajudantes, auxiliares de ensino, que era o meu caso. Eu entrei na faculdade e, quando eu estava terminando o meu curso, fui convidada pelo catedrático para dar aula em seu lugar. O catedrático tinha um nome vinculado à faculdade, mas não tinha como obrigação dar aulas. Às vezes, ele nem passava pela faculdade, não se sabia dele. Só se sabia dos catedráticos que eles eram autoridades ali, tinham um nome em sua área, mas o que eles faziam, para nós, era inteiramente desconhecido.

Bem, foi assim que eu conheci Guerreiro Ramos: ao contrário do catedrático, um professor que se fazia presente, que dava aulas nessa instituição que era uma grande inovação. O ISEB veio naquela onda de novidades do presidente Juscelino Kubitschek. Foi criado em nome do Juscelino, com o apoio do Juscelino e como parte daquela presidência dinâmica do Juscelino. Até hoje eu lembro o endereço: Rua das Palmeiras, n. 55. Lá íamos nós procurar, nem sabíamos onde era essa Rua das Palmeiras, era tudo novidade. Foi o professor Alberto Latorre de Faria, um colega nosso que se tornou titular da área de Organização de Cursos e Conferências do ISEB, que nos convidou, a mim e a outras pessoas de meu grupo, para conhecermos a instituição.

Eu conheci o professor Guerreiro Ramos logo no início. Ele dava aulas de Sociologia. Tudo para nós era novidade, desde os próprios títulos até o conteúdo das disciplinas que nos eram oferecidas.

No Departamento de Administração e Serviço Público (DASP), Guerreiro Ramos já tinha um bom nome. Ele era considerado uma 
pessoa de categoria, era conhecido, porque falava bem. Quem assistia às aulas dele aprovava. Ele já tinha esse reconhecimento. Além disso, seus trabalhos constavam das publicações do ISEB, eram trabalhos publicados sob a tutela do Instituto. Mas a divulgação desses trabalhos não passava pelos meios oficiais, era passada de boca a boca. Nós andávamos atrás de bons professores, como ele. Tínhamos sede dessa relação, porque a maioria dos grandes professores, por tradição não dava aulas, ou dava apenas as aulas inaugurais; quem enfrentava o dia a dia das salas de aula eram os assessores dos catedráticos. Os cursos do ISEB eram abertos e gratuitos, a entrada era informal e não se exigia o curso secundário dos candidatos. As pessoas se aproximavam e eram levadas umas pelas outras. E o Instituto ganhou prestígio, sobretudo pela qualidade dos professores e pela atualidade dos temas tratados. Era uma grande oportunidade de se conhecer professores e intelectuais de fora do circuito universitário oficial.

Dessa forma, ao conhecê-lo eu não encontrei Guerreiro Ramos sozinho, mas como parte do grupo que criava e atuava no ISEB, como a professora Maria Yedda Linhares e intelectuais como Roland Corbisier, Hélio Jaguaribe, Nélson Werneck Sodré, entre outros. Foi o mesmo professor Alberto Latorre de Faria que me apresentou a Guerreiro Ramos e nós começamos a ter uma boa relação, mas nunca fomos amigos no sentido mais profundo do termo. Nunca nos frequentamos, por assim dizer.

Na época, eu iniciava o meu interesse em estudar a situação da mulher na sociedade brasileira e procurava vincular meu pensamento sociológico com essa problemática. Mas havia pouca oportunidade para isso, não se discutia esse assunto, e o ISEB não era exceção. Só depois, na década de 1970, com a publicação do livro pioneiro de Heleieth Saffioti $^{2}$, o tema das relações de gênero passou a ser discutido de forma sistemática dentro da Sociologia. Já com relação à questão racial, havia alguns trabalhos, no contexto da pesquisa da UNESCO no início da década de 1950. Guerreiro Ramos teve a iniciativa de contestar, junto com Abdias Nascimento e outros intelectuais do Teatro Experimental do Negro, o trabalho sociológico produzido sobre relações raciais no Rio de Janeiro. Entretanto, de uma forma generalizada, na época não 
havia um discurso acadêmico sobre a questão racial, esse não era um tema discutido. E Guerreiro Ramos, por ser mulato - e não propriamente "negão", para recorrer a um linguajar popular - era reconhecido como tal: mulato. Creio que se ele fosse visto como "negão", não seria acolhido, pois não havia, então, nenhum professor negro na faculdade. E aluno, se havia algum, era exceção e um assunto não mencionado. Alguns alunos negros se matriculavam, mas não chegavam a completar o curso. Faziam uma passagem transitória, pois não houve nenhum caso de aluno negro que completasse o curso, na área das ciências sociais, na Faculdade Nacional de Filosofia, pelo menos durante os anos em que lá lecionei.

A obra de Guerreiro Ramos foi importantíssima para a sociologia brasileira. Em primeiro lugar, nós só tínhamos acesso à literatura da sociologia americana e francesa - por assim dizer, enlatada, i.e., traduzida para o português. Nós, no Rio de Janeiro, não tínhamos produção própria. São Paulo já tinha alguma coisa nessa área, já tinha gente estudando, já se conhecia o pensamento dos sociólogos da Universidade de São Paulo, mas quando chegou aqui essa injeção de cultura do ISEB, que vinha preocupado com a questão brasileira, para nós foi uma surpresa e ao mesmo tempo um estimulo. Nada que vá indicar "nascia um novo Brasil", mas para nós se abriram novas oportunidades que até então não tínhamos. Inclusive a própria bibliografia brasileira era escassa. Pouca gente escrevia sobre sociologia, mas, daí pra frente, a coisa melhorou: saíram, inclusive, a "Introdução crítica à sociologia brasileira" (1957) e "A redução sociológica" (1958)4, do próprio Guerreiro Ramos.

Na política, Guerreiro teve uma atuação marcante como deputado. Mas no ISEB ele não lecionava ciência política, lecionava sociologia. Naquele momento havia uma concorrência entre as pessoas que faziam sociologia, uma competição, quase que não se expressava, mas havia. Várias pessoas trabalhavam numa mesma área, mas não interagiam, ficava cada uma na sua raia. Em São Paulo já havia algum espírito de equipe. Isso nós sabíamos, porque chegavam até nós seus trabalhos, os livros que eles escreviam. Florestan Fernandes e o seu grupo, com Otávio Ianni e outros, produziam trabalhos em equipe, desenvolviam 
um espírito de equipe. O grupo trabalhava junto, escrevia junto, produzia junto. Aqui no Rio era o vire-se, arranje-se como puder.

Guerreiro Ramos atuou no Congresso como deputado do Partido Trabalhista Brasileiro (PTB), suplente de Leonel Brizola, e o regime militar logo cassou o seu mandato, já no início da ditadura. Ele foi, então, para os Estados Unidos, onde lecionava em uma universidade da Califórnia. Mais tarde, ele voltou clandestino. Naquele tempo era assim, a gente ia sair, voltava, e de vez em quando alguém telefonava e dizia: "Moema, some". Porque a repressão andava atrás das pessoas como eu, como ele, assumidamente "de esquerda"; então de vez em quando, alguém avisava. Tinha alguém da polícia que de certo tomava conhecimento das coisas e corria logo no telefone: "Moema, some". A gente sumia por uns tempos, nem atendia mais telefone, até passar o pânico.

Eu trabalhava na PUC-RJ nessa época. A PUC foi a instituição que nos acolheu quando veio a aposentadoria forçada. Eu abri o jornal em um sábado de manhã e lá estava o meu nome, primeiro na lista dos aposentados à força pelo chamado Ato Institucional n. 1. Aposentada por tempo de serviço. Eu que tinha recém entrado no serviço público, estava em início de carreira, aposentada do Instituto de Filosofia e Ciências Sociais da Universidade Federal do Rio de Janeiro, por tempo de serviço! Estava na rua, sem emprego, com um salário ridículo. Eu que vivia do meu trabalho, que sempre vivi do meu trabalho, fiquei em pânico. Fui dar aula lá pelo interior do estado em pequenas escolas onde eu podia dar sociologia, onde essa matéria era oferecida. Aliás, poucas escolas tinham essa matéria nos seus currículos. Eram raras, e por coincidência algumas dessas estavam sem professor. Então comecei a dar aulas assim. Foi um tempo horrível, total insegurança com relação à carreira.

Bem, mais tarde, para minha surpresa, quando Guerreiro Ramos voltou clandestinamente do exílio ele mandou me chamar para conversar. Eu fiquei admirada. Não sei nem onde foi, porque a gente fazia questão de treinar para esquecer endereços, para, no caso de apertar, não saber. Eu sei que ele mandou me chamar, não lembro por intermédio de quem. Ele queria conversar comigo. E foi ótimo. 
Tivemos mais encontros depois, em outros lugares, e foi uma relação boa. No início era uma relação formal, mas ele era uma pessoa muito simpática e, sobretudo, um estudioso. Ele sabia que era procurado pela polícia, que não era pessoa grata e que essa situação não tinha saída à vista. Ele não explicou porque me chamou e nem eu perguntei. Eu não tinha essa intimidade, mas gostei de ter sido chamada. Não sei se ele chamou outras pessoas também. Mas naquela época, quando a gente se encontrava, quando tinha a oportunidade de falar com uma pessoa que tinha esses elos, para nós era uma maravilha, porque fora disso a gente estava sempre com medo. Tudo o que você pudesse conversar podia dar encrenca. Tanto é que eu perdi o emprego. Eu abri o jornal e estava aposentada, que surpresa terrível: o regime me tirara o tapete, eu fiquei no ar.

Professores como Guerreiro Ramos encontravam trabalho e não tiveram problema no exterior. E ele não ficou mal com o Brasil, ele queria voltar, tinha família aqui, amigos. Antes de sair ele fazia parte de um time de professores interessado na realidade brasileira, sem compromisso com o status quo. Mas havia muitas restrições para ele aqui no campo do magistério oficial.

Minha convivência com Guerreiro Ramos se resume a isso; acho que não há mais nada para contar. Para mim, foi um prazer esse convívio com uma pessoa que teve um papel tão importante nos primórdios do pensamento sociológico brasileiro. Guerreiro Ramos deixou sua marca definitiva nessa área da sociologia acadêmica.

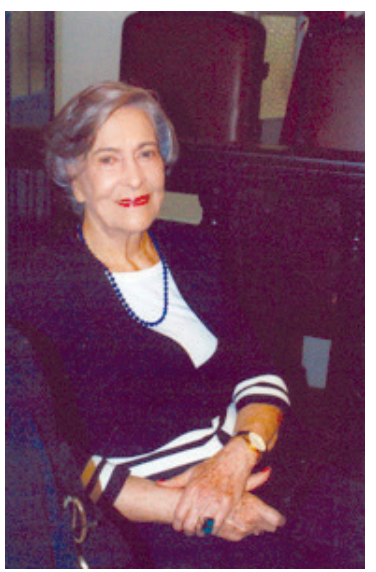

\section{Moema Toscano}

Gaúcha de Garibaldi, Moema Toscano, normalista diplomada em Educação Física, foi para o Rio de Janeiro no início dos anos de 1950 para continuar sua formação. Em 1952 inscreveu-se na Faculdade Nacional de Filosofia, onde se graduou em Ciências Sociais e em seguida passou a lecionar até se aposentar aos 75 anos, na atual Universidade Federal do 
Rio de Janeiro. Lecionou também na PUC-RJ e frequentou o Instituto Superior de Estudos Brasileiros (ISEB), onde conheceu Guerreiro Ramos, que lecionava Sociologia e Ciência Política.

Em abril de 2012, Moema Toscano recebeu a medalha Chico Mendes de Resistência, concedida pelo Grupo Tortura Nunca Mais, que registra outra parte de sua biografia: "Perseguida pela ditadura, ficou impedida de exercer o magistério por muitos anos. Cortavam-lhe, assim, os meios de sobrevivência. Anos depois, ficou sabendo que em sua ficha no DOPS constava apenas: "amiga de notórios comunistas", segundo depoimento do Deputado Rubens Berardo. Disse Moema: "Eu me recusei a receber a indenização pecuniária que ofereceram. Não aceito converter a anistia em pacto pecuniário. Não perdoei o pecado que cometeram comigo; não 'anistiei', por assim dizer, os responsáveis pela minha 'expulsão' do serviço público".

Amiga de notórias personalidades, a mestra querida e admirada por seus alunos, sofreu a experiência constrangedora da exclusão das salas de aula, situação que deixou marcantes cicatrizes no meio acadêmico nacional. Moema cita colegas e professores, seus amigos que não resistiram ao arbítrio e morreram de pesar. Impedida de lecionar na Universidade Federal, durante a ditadura, ela foi professora de inúmeros colégios na Baixada Fluminense, em Duque de Caxias, e mesmo na capital federal, até a volta do regime democrático, em 1980.

Feminista, Moema é uma das fundadoras do Centro da Mulher Brasileira (CMB). Em 1975, na segunda onda do movimento mundial de mulheres, ela participou da mobilização da sociedade para o tema, na preparação das celebrações do Dia Internacional da Mulher, no México. E participou das muitas lutas da sociedade civil, nos anos de 1970 e 1980, em que as minorias sociais buscavam expressão. O movimento feminista desenvolvia ação na causa específica de reconhecimento e de transformação do papel da mulher no século XX. Para ela, o movimento social mais importante no século passado foi o das mulheres, já que o feminismo mudou a vida de todos.

Professora, ativista política e escritora, Moema Toscano participou de congressos nacionais e internacionais representando o pensamento 
da mulher feminista brasileira. Realizou pesquisas e participou da formação de novas propostas das mulheres na luta por seus direitos sociais e políticos. Sua vida profissional esteve sempre ligada ao magistério, do ensino primário à pós-graduação.

\section{Livros Publicados:}

"Introdução à Sociologia Educacional", 22. edição. Editora Vozes;

"Teoria da Educação Física Brasileira";

"Mulher, Trabalho e Política - Caminhos cruzados do feminismo", com Fanny Tabac (1976);

"A Revolução das Mulheres" - Um Balanço do Feminismo no Brasil, com Mirian Goldenberg (1992);

"Estereótipos Sexuais na Educação - Um manual para o educador" (2000).

\section{Notas}

1 Depoimento concedido a Elisa Larkin Nascimento em 10 de fevereiro de 2016 e a Ilka Boaventura Leite em 2 de março de 2016.

2 Heleieth Saffioti, A mulher na sociedade de classes: mito e realidade. Tese de livre docência , Faculdade de Filosofia, Ciências e Letras de Araraquara, Universidade Estadual de São Paulo (UNESP), 1967, publicada pela Editora Vozes, 1976.

3 Guerreiro Ramos, Alberto. Introdução crítica à sociologia brasileira. Rio de Janeiro: Editorial Andes, 1957.

4 Guerreiro Ramos, Alberto. A redução sociológica. Rio de Janeiro: Tempo Brasileiro, 1958.

Recebido em 28/02/2016

Aceito em 1\%03/2016 